\title{
ANÁLISE DE SENSIBILIDADE PARA O PARÂMETRO CONDUTÂNCIA NA CONDIÇÃO DE CONTORNO DE TIPO 3 DO MODELO MODFLOW
}

\author{
Carlos Alberto de Carvalho Filho ${ }^{1}$ \\ Stela Dalva Santos Cota
}

\begin{abstract}
RESUMO
A escolha das condições de contorno mais adequadas para simular matematicamente sistemas hidrogeológicos é uma etapa essencial do processo de modelagem. Longe de ser uma tarefa trivial, ela depende do conhecimento pormenorizado do sistema a ser simulado e das especificidades matemáticas do modelo escolhido. Este trabalho tem por objetivo apresentar uma análise de sensibilidade para o parâmetro Condutância na condição de contorno GHB do modelo de fluxo de água subterrânea MODFLOW. Além disso, o trabalho apresenta uma análise comparativa das características matemáticas de quatro pacotes ou módulos do MODFLOW, que são formas de implementação da condição de contorno de tipo 3 (GHB, Rio, Dreno e EVT). Os resultados obtidos vêm contribuir para uma maior compreensão do funcionamento das rotinas matemáticas que descrevem a condição de contorno de tipo 3 , auxiliando, portanto, os hidrogeólogos a desenvolver modelos que melhor representem a realidade.
\end{abstract}

\begin{abstract}
The choice of the more adequate boundary conditions to simulate mathematically hydrogeologic systems is an essential task of the modeling process. Far from being a trivial task, it depends on the detailed knowledge of the system being simulated and the mathematical characteristics of the chosen model. This work presents a comparative analysis of the mathematical characteristics of four packages or modules of the ground water flow model, MODFLOW, that implement type 3 boundary conditions (GHB, River, Drain and EVT), and a sensitivity analysis for the Condutance parameter. By improving the understanding of the type 3 boundary conditons of the MODFLOW code, the results may help the hydrogeologist to develop models that better represent the reality.
\end{abstract}

Palavras-chave - Águas subterrâneas; Modelagem; MODFLOW.

\section{INTRODUÇÃO}

Em termos gerais, modelos matemáticos de simulação do fluxo da água subterrânea consistem de uma equação governante, condições de contorno e condições iniciais $[1,2,3]$. A equação principal descreve o processo físico que ocorre no sistema. As condições iniciais definem a distribuição de carga no início da simulação. As condições de contorno são enunciados matemáticos que especificam a variável dependente (carga) ou a derivada da variável dependente (fluxo) nos limites ou fronteiras do domínio do problema.

Em termos matemáticos, as condições de contorno hidrogeológicas são represen- tadas por três tipos distintos [1]: tipo 1 contorno com carga especificada; tipo 2 contorno com fluxo especificado; tipo 3 contorno com fluxo dependente da carga. Com relação a este último tipo, o fluxo através do contorno é calculado a partir do valor da carga.

O presente trabalho tem por objetivo apresentar uma análise de sensibilidade para o parâmetro Condutância na simulação de um caso hipotético envolvendo condição de contorno "General Head Boundary" (GHB) e o rebaixamento do aqüífero através de bombeamento. Além disso, é feita uma análise comparativa das características matemáticas de quatro pacotes ou módulos do código de computador MODFLOW

\footnotetext{
${ }^{1}$ Centro de Desenvolvimento da Tecnologia Nuclear - CDTN/CNEN, Rua Prof. Mário Werneck, s/no., CP 941, 30.161-970, Belo Horizonte, MG - Fone (31) 3499-3351 - sdsc@urano.cdtn.br
} 
[1,4,5]: GHB, Rio, Dreno e Evapotranspiração (EVT). Todos representam condições de contorno do tipo 3 , matematicamente funcionam de forma muito similar, e têm por finalidade simular os efeitos do fluxo entre os contornos e o sistema aqüífero. Ressalta-se que a Condutância é a principal fonte de incertezas ao se utilizar tais pacotes.

\section{CARACTERÍSTICAS MATEMÁTICAS DOS MÓDULOS}

\section{Módulo "General Head Boundary" (GHB)}

Este módulo representa a forma mais geral dentre as quatro opções de aplicação da condição de contorno em análise (tipo 3) disponíveis no modelo MODFLOW. Pode-se dizer que os demais foram desenvolvidos a partir de modificações deste módulo, com a adição de características que permitem a simulação de fenômenos particulares.

Basicamente, a diferença dos outros pacotes com relação ao GHB dá-se através dos limites de validade da equação utilizada para o cálculo da descarga de água. Enquanto a equação base para cálculo da descarga é válida para todos os valores de carga no pacote $\mathrm{GHB}$, os demais pacotes se caracterizam pela existência de limites para sua validade.

No modelo MODFLOW [4], para a condição de contorno do tipo 3 , a equação básica para o cálculo da descarga de água $(Q D)$ entre o contorno e o aqüífero é dada por

$$
Q D=\text { cond } .(d-h)
$$

onde $h$ é a carga hidráulica na célula com atribuição de condição de contorno, $d$ é uma elevação relativa à condição de contorno e cond é um parâmetro de proporcionalidade.

Pode-se observar que a descarga de água trocada entre o aqüífero e o contorno é proporcional à diferença entre $d$ e $h$ na célula. A constante de proporcionalidade da equação de descarga, denominada condutância (cond), descreve o grau de conectividade entre o contorno e o aqüífero na célula especificada como contorno GHB. Por ser um termo matemático de proporcionalidade, a condutância é essencialmente um parâmetro de calibração da equação, mas, em alguns pacotes, é possível se estabelecer uma relação com parâmetros físicos, como será discutido oportunamente.

Neste ponto, deseja-se ressaltar a distinção entre a carga $(h)$ e a elevação $(d)$, por ser comum a confusão sobre o significado desses valores. A condição de contorno deve ser visualizada como uma fonte ou sumidouro de água, externa ao domínio, embora ligada a ele através das células nas quais esta condição foi implantada. Nesta fonte ou sumidouro, o nível da água é mantido constante, sendo igual à elevação. A carga representa o valor da carga hidráulica do aqüífero nas células especificadas como contorno. Portanto, a carga é relativa ao aqüífero, enquanto $d$ é um parâmetro da condição de contorno.

A Figura 1 traz uma representação da ligação entre uma célula do domínio (à esquerda) e o contorno GHB (à direita). Observa-se que a condição de contorno é mantida com carga constante $(d)$, enquanto o domínio possui carga variável (h). É intuitivo supor que quando a carga na célula é maior do que $d$, a condição de contorno atua como um sumidouro de água. Por outro lado, quando a carga cai abaixo da elevação, a condição de contorno passa a atuar como fonte de água para o aqüífero. A área cinza na Figura 1 representa um elemento de resistência à passagem de água entre o contorno e o aqüífero, que é descrito matematicamente através do parâmetro condutância.

O pacote GHB simula a retirada ou fornecimento de água do aqüífero nas células do domínio especificadas como contorno. A Figura 2 mostra, de forma esquemática, o funcionamento deste pacote em uma célula do domínio, onde a representação da condição de contorno é mostrada na sua parte central. Para diferentes valores de carga, é apresentada a expressão matemática que calcula a descarga entre o domínio e a condição de contorno (QD).

Nesta figura, as linhas $h_{s}$ e $h_{f}$ indicam, respectivamente, o topo e o fundo da célula na qual foi atribuída a condição de contorno. O parâmetro $d$ representa o valor do nível da água no contorno GHB. A carga do aqüífero na célula $(h)$ é mostrada em cinza, variando de valores superiores a $d$ (podendo, inclusive, ser superior a $h_{s}$ ) até valores inferiores a $d$ (devendo ser superiores a $h_{f}$ ).

Pode-se observar na Figura 2 que, quando a carga for maior do que $d$, a descarga $(Q D)$ é negativa, indicando que a água está sendo retirada do aqüífero. Nota-se que, no pacote GHB, não há limite superior para a descarga. Este valor negativo de descarga é tanto maior (em módulo) quanto 
maior for a carga, podendo ser, inclusive, superior ao topo da célula $\left(h_{s}\right)$.

À medida que a carga cai, o valor de QD também cai, em módulo, atingindo o valor zero quando $h=d$. A partir deste ponto, a descarga torna-se positiva, indicando que a água está entrando no aqüífero. Neste caso, quanto menor o valor de $h$, maior será o valor de $Q D$, isto é, mais água fluirá através do contorno para o aqüífero.

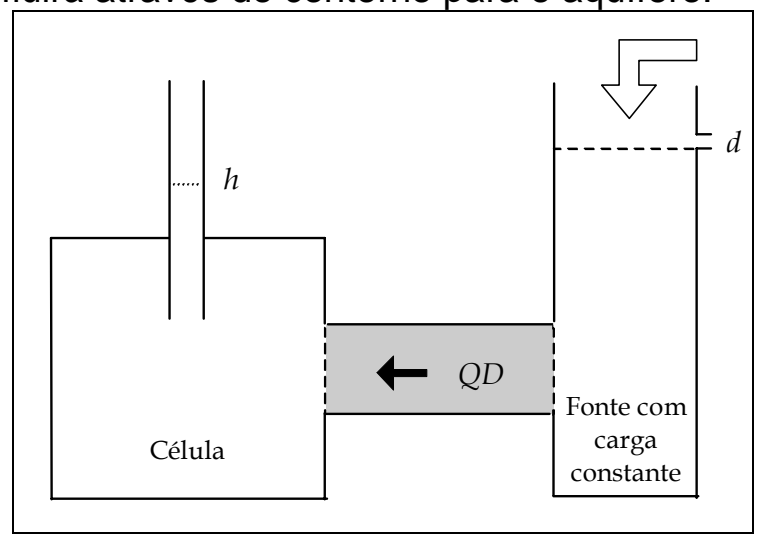

Figura 1. Representação da ligação entre a célula do domínio e a condição de contorno [4]

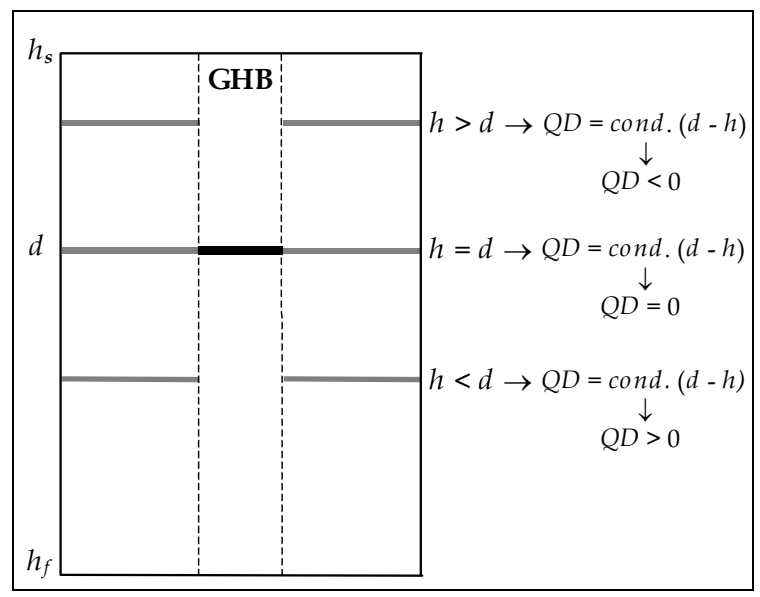

Figura 2. Esquema de funcionamento do pacote $\mathrm{GHB}$

No entanto, há um limite inferior para $h$ que é uma imposição do próprio modelo, não sendo inerente à condição de contorno. Quando $h$ atinge o fundo da célula, esta torna-se inativa (célula seca). Assim, a partir da Eq. 2, que é uma modificação da Eq. 1 para $h$ tendendo a $h_{f}$, pode-se calcular, para uma determinada célula do domínio, a maior descarga de água possível que entra no aqüífero proveniente do contorno GHB.

$Q D_{\max }=\lim _{h \rightarrow h_{f}} Q D(h)=$ cond $\left(d-h_{f}\right)$

Concluindo, o módulo GHB se caracteriza pela inexistência de limites para a validade da Equação (1), em termos de carga, que sejam inerentes à própria condição $\mathrm{GHB}$, ao contrário dos demais módulos abordados neste trabalho, como será discutido mais adiante.

\section{Módulo Rio}

O pacote Rio simula o fluxo de água entre águas superficiais e o aqüífero nas células do domínio onde esta condição de contorno foi atribuída. A Figura 3 mostra, de forma esquemática, o funcionamento deste pacote, para diferentes valores de carga, com a expressão para cálculo da descarga entre a célula do domínio com atribuição de condição de contorno e o contorno.

Analisando a Figura 3, pode-se observar que, da mesma forma que ocorre no módulo GHB, a descarga de água trocada entre o aqüífero e o contorno é proporcional à diferença entre $d$ e $h$, sendo a Equação (1) válida também para este pacote [4]. A diferença, neste caso, é que há limites para sua validade, como será visto a seguir.

Em comparação com a Figura 2, a Figura 3 apresenta uma diferença significativa. Pode-se observar nesta figura que o módulo Rio apresenta outro parâmetro além da elevação da água (d). Matematicamente, este parâmetro, denominado RBOT, é o limite para mudança da validade da equação de cálculo de descarga na célula. No entanto, estabelecendo uma correlação com o fenômeno físico, é possível relacioná-lo com a cota do fundo do leito do rio.

Analisando a Figura 3, pode-se verificar que, para valores de $h$ superiores a $R B O T$, a relação entre a descarga e a carga para o pacote Rio é exatamente igual à observada para o pacote GHB (Equação (1)). Quando $h$ torna-se igual a RBOT, o valor de $Q D$ atinge seu valor máximo, igual a

$$
Q D=\text { cond } .(d-R B O T)
$$

Para valores de carga inferiores a RBOT, a Eq. 1 não é mais válida. O valor da descarga passa a ser constante, igual ao seu valor máximo, dado pela Eq. 3, independentemente da carga.

A constante de proporcionalidade da equação de descarga, aqui também denominada condutância (cond), descreve o grau de conectividade entre o contorno e a célula do domínio onde esta condição de contorno foi atribuída. Apesar de ser um termo matemático de proporcionalidade, é possível se estabelecer uma relação com parâmetros 
físicos de um rio, tais como a espessura e a condutividade hidráulica do leito do rio.

Assim, a condutância do pacote Rio pode ser estimada [4] para determinada célula através da equação

$$
\text { cond }_{\text {Rio }}=\frac{K . L W}{E}
$$

onde $K[\mathrm{~L} / \mathrm{T}]$ é a condutividade hidráulica do material que compõe o leito do rio, $L$ [L] é o comprimento do rio na célula para a qual a condutância está sendo calculada, $W$ [L] é a largura do rio e $E[L]$ é a espessura do leito do rio.

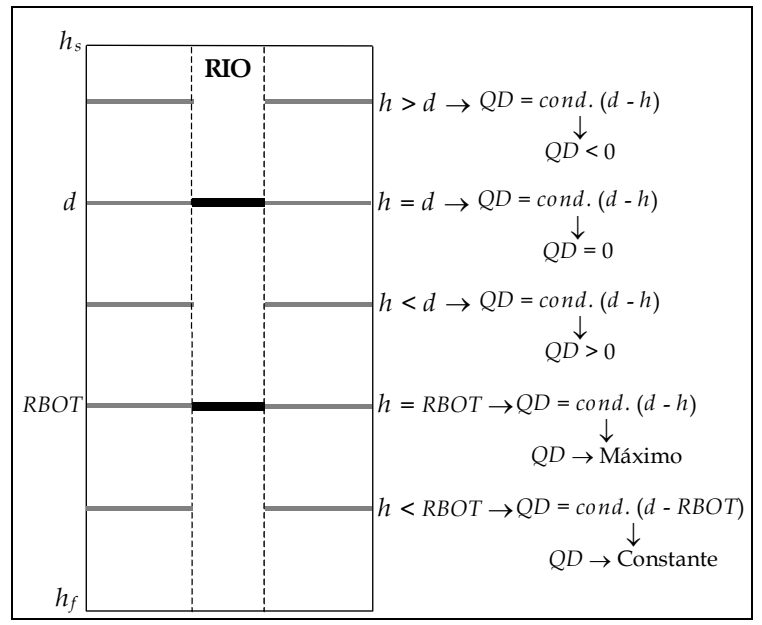

Figura 3. Esquema de funcionamento do pacote Rio

Em resumo, a diferença entre os pacotes de condição de contorno GHB e Rio está relacionada com o limite de validade da equação geral de cálculo de descarga (Eq. 1). Enquanto o módulo GHB não apresenta um limite para o valor da descarga para a faixa válida de valores de carga $\left(h>h_{f}\right)$, no módulo Rio, quando $h$ se torna inferior a $R B O T$, os valores da descarga são fixados a um valor máximo, calculado pela Eq. 3 .

\section{Módulo Dreno}

Este pacote de condição de contorno de tipo 3 se caracteriza por atuar apenas como um sumidouro de água do aqüífero. Quando a carga na célula na qual foi atribuído este contorno atinge determinado limite inferior, o fluxo de água cessa e o contorno se torna inativo. A equação base de cálculo de descarga (Eq. 1) é válida até este limite de carga, abaixo do qual a descarga tornase nula [4]. A Figura 4 mostra, de forma esquemática, o funcionamento deste pacote, para diferentes valores de carga.
Comparando-se a Figura 4 com a Figura 2, pode-se verificar que, para valores de $h$ superiores a $d$, a relação entre a descarga e a carga para o pacote Dreno é exatamente a mesma da observada para o pacote $\mathrm{GHB}$, sendo regida pela Eq. 1. Entretanto, para valores de carga inferiores a $d$, a Eq. 1 perde a validade e a descarga tornase nula.

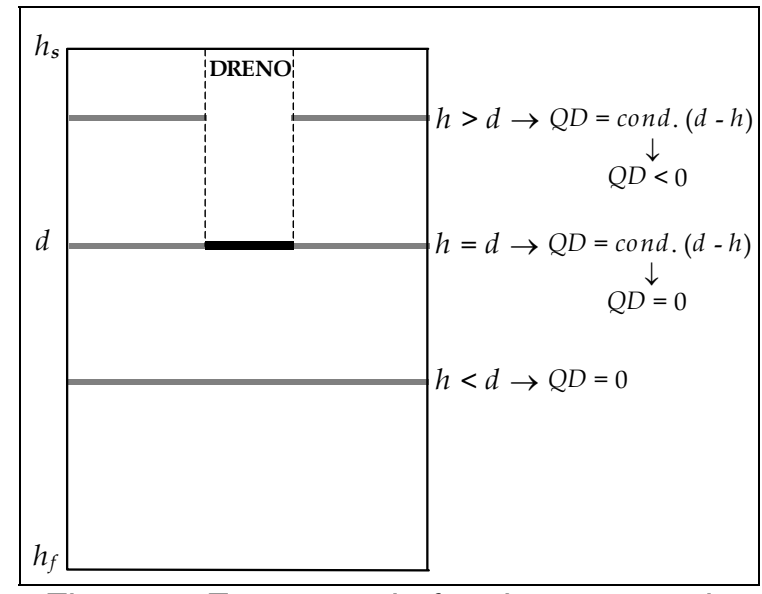

Figura 4. Esquema de funcionamento do pacote Dreno

Desta forma, o módulo Dreno pretende simular o comportamento passivo dos drenos. Estas estruturas retiram água do aqüífero, promovendo o rebaixamento de seu nível. Entretanto, ao contrário dos grandes corpos d'água, não apresentam um caudal de água suficiente para alimentar o aqüífero. Assim, quando há um rebaixamento expressivo do nível d'água no aqüífero, estas estruturas deixam de exercer influência.

Como foi feito na análise do pacote Rio, também aqui é possível se estabelecer uma relação entre a constante de proporcionalidade (cond) e os parâmetros físicos de um dreno. Para a simulação de um dreno aberto, a condutância pode ser estimada utilizando a mesma expressão da condutância definida no módulo Rio (Eq. 4), onde os termos têm o mesmo significado.

Para drenos fechados (dutos), entretanto, a estimativa da condutância é bem mais complexa. A resistência à entrada de água no dreno sofre a influência de vários fatores, tais como o número e o tamanho das aberturas presentes no conduto drenante; a condutividade hidráulica nas proximidades do dreno; a quantidade, o tipo e a condutividade hidráulica do material que normalmente obstrui as aberturas, etc. Diante do exposto, na prática é mais fácil de- 
terminar a condutância de drenos fechados a partir de calibragem do modelo.

Concluindo, em comparação com o módulo GHB, o módulo Dreno apresenta um limite inferior para a validade da equação de cálculo da descarga $(h=d)$, abaixo do qual a descarga torna-se nula e este contorno deixa de atuar no sistema.

\section{Módulo Evapotranspiração (EVT)}

O pacote EVT simula os efeitos da evapotranspiração sobre o aqüífero, isto é, procura representar as perdas de água que ocorrem na zona saturada da água subterrânea, devido a ação conjunta da transpiração das plantas e da evaporação.

No módulo EVT, a Eq. 5 é a base de cálculo para a descarga (QD), embora não seja válida para determinados valores de carga $(h)$ da célula onde esta condição de contorno foi empregada, como será discutido oportunamente [4].

$$
Q D=-Q_{\max } \cdot\left(\frac{h-d}{h_{s}-d}\right)
$$

$\mathrm{Na}$ equação anterior, $Q_{\max }$ é a descarga máxima e $d$ é a elevação de extinção do efeito da evapotranspiração, sendo calculada pela equação:

$$
d=h_{s}-p_{\text {ext }}
$$

onde $p_{\text {ext }}$ é a profundidade de extinção para a evapotranspiração, que deve ser fornecida pelo usuário.

Pode-se observar a semelhança entre as Eq. 1 e 5. Em ambas, a descarga é estimada como sendo diretamente proporcional à diferença entre a carga hidráulica na célula (h) e o parâmetro da condição de contorno (d). Para os pacotes GHB, Rio e Dreno, a constante de proporcionalidade é dada pela condutância (cond), enquanto que, para o módulo EVT, esta constante é dada por $Q_{\max } /\left(h_{s}-d\right)$. Conforme pode-se observar na Figura 5, quando a carga da célula onde se aplicou o contorno EVT eleva-se acima da superfície de evapotranspiração $\left(h_{s}\right)$, o aqüífero perde água através de evapotranspiração à taxa constante, dada por $Q_{\max }$. Portanto, neste caso, a Eq. 5 deixa de ser válida.

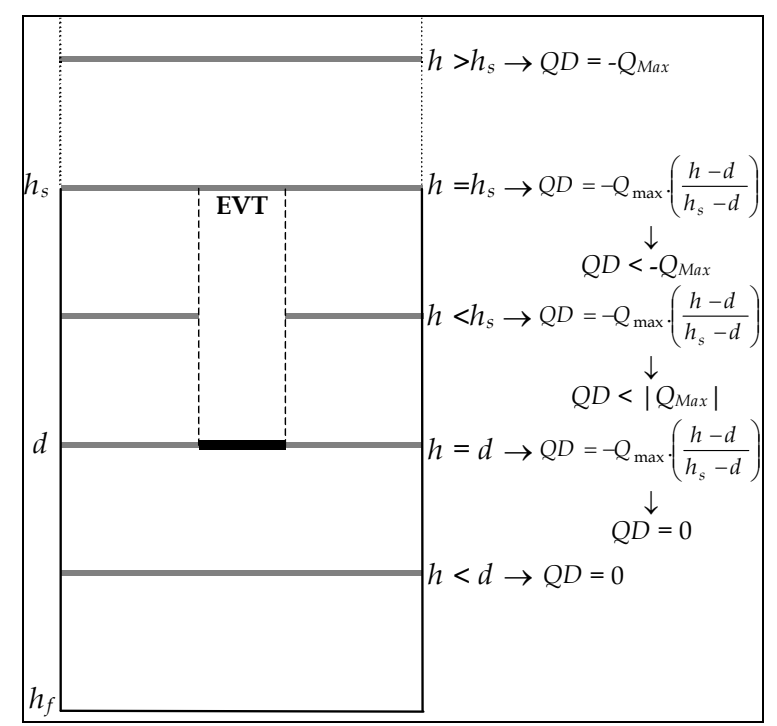

Figura 5. Esquema de funcionamento do pacote EVT

Na situação em que a carga é menor ou igual a $h_{s}$ e maior ou igual a $d\left(h_{s} \geq h \geq d\right)$, o aqüífero perde água por evapotranspiração com taxa descrita pela Eq. $5(Q D<0)$. Quando a carga atinge um valor igual ao da elevação de extinção $d$, a descarga é nula, conforme pode-se verificar através da Eq. 5 . Para valores de carga inferiores à elevação de extinção, a Eq. 5 deixa de ser válida e $Q D$ torna-se nula. Portanto, neste caso, a evapotranspiração torna-se inativa.

Com relação ao módulo GHB, o módulo EVT apresenta dois limites para a validade da equação básica. Um limite superior $\left(h=h_{s}\right.$ ), quando a descarga atinge seu valor máximo (em módulo), tornando-se constante para os valores de carga superiores a $h_{s}$. E um limite inferior $(h=d)$, abaixo do qual a descarga torna-se nula.

\section{ANÁLISE DE SENSIBILIDADE}

O termo de proporcionalidade da Eq. 1, a Condutância, é um parâmetro que deve ser fornecido ao modelo ao se utilizar a maioria dos pacotes de condição de contorno de tipo 3 (GHB, Rio e Dreno). Apesar do sentido físico atribuído a este parâmetro para alguns pacotes (Rio e Dreno), este é um termo que, essencialmente, é definido por calibração ou ajuste do modelo aos dados experimentais disponíveis.

Com o objetivo de auxiliar no processo de escolha dos valores de condutância a serem utilizados, apresenta-se, nesta seção, uma análise de sensibilidade para este parâmetro, realizada observando-se a carga resultante em uma célula com atribuição de 
condição de contorno de tipo 3 devido a um poço em bombeamento. A condição de contorno foi simulada utilizando o pacote GHB. A análise se restringiu à faixa de validade da Eq. 1. Todas as simulações foram realizadas utilizando o software Visual MODFLOW [6].

\section{Descrição do caso simulado}

O caso simulado foi baseado em caso similar publicado pela U.S. Environmental Protection Agency - U.S.EPA [5]. O aqüífero simulado é do tipo livre, homogêneo e isotrópico. O domínio idealizado para a simulação compõe-se de uma única camada, com $50 \mathrm{~m}$ de espessura, $110 \mathrm{~m}$ de comprimento (direção $x$ ) e $110 \mathrm{~m}$ de largura (direção y), perfazendo uma malha de 11 colunas por 11 linhas. Um poço de bombeamento foi implantado na Célula $(6,1)$ (Linha 6, Coluna 1), operando continuamente com taxa de extração de $300 \mathrm{~m}^{3} /$ dia. Os dados de entrada característicos do aqüífero e os parâmetros da simulação encontram-se na Tabela 1. A Figura 6 mostra a descrição do domínio.

A variação da resposta do modelo, em termos de carga hidráulica na Célula $(6,11)$, foi observada ao se variar o valor da condutância entre 1,6 e 14,4 m²/dia, correspondendo à variação percentual de -80 a $80 \%$ em relação ao valor assumido como padrão $\left(8 \mathrm{~m}^{2} /\right.$ dia). O parâmetro Elevação foi fixado em 840 m. Os resultados são apresentados na Tabela 2 para 10 e 80 dias de simulação. A Figura 7 mostra os valores de carga hidráulica grafados em função da condutância para os dois tempos de simulação. A Figura 8 apresenta os mesmos resultados grafados em termos de variação percentual de condutância e carga hidráulica em relação aos valores-padrão: $8 \mathrm{~m}^{2} /$ dia para a condutância e os correspondentes valores de carga hidráulica obtidos $(842,69$ e 836,91 m a 10 e 80 dias, respectivamente).

Tabela 1. Dados gerais da simulação de análise de sensibilidade

\begin{tabular}{cc}
\hline Parâmetro & Valor \\
\hline Condutividade hidráulica & $1 \mathrm{~m} / \mathrm{dia}$ \\
Coef. de armazenamento & 0,09 \\
Cota do topo do aqüífero & $850 \mathrm{~m}$ \\
Cota do fundo do aqüífero & $800 \mathrm{~m}$ \\
Espaçamento da grade & $10 \mathrm{~m}$ \\
Carga inicial & $850 \mathrm{~m}$ \\
Taxa de bombeamento & $300 \mathrm{~m}^{3} / \mathrm{dia}$ \\
Tempo de simulação & $150 \mathrm{dias}$ \\
\hline
\end{tabular}

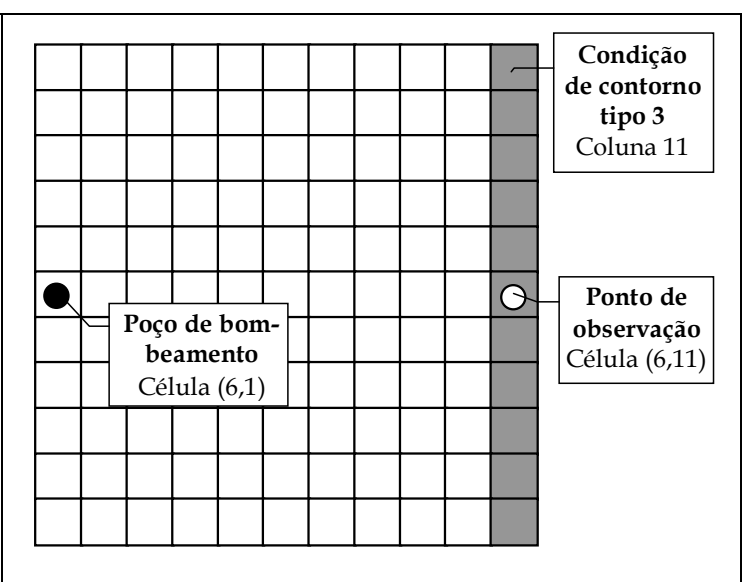

Figura 6. Domínio do caso simulado na análise de sensibilidade para o parâmetro Condutância

\section{DISCUSSÃO DOS RESULTADOS}

A primeira questão a ser observada sobre os resultados da análise de sensibilidade é que o aumento do valor da condutância exerce efeitos opostos no tempo 10 dias e 80 dias. A carga hidráulica calculada pelo modelo utilizando o pacote GHB tende a diminuir com o aumento na condutância para o tempo de 10 dias e, aos 80 dias de simulação, a tendência é de aumento da carga hidráulica.

A razão para este fato é que, ao se aumentar a condutância, as descargas entre o contorno e o aqüífero se tornam maiores e as funções da condição de contorno, tanto a função fonte quanto a função sumidouro, tornam-se mais eficientes. Na primeira etapa da simulação, que vai até aproximadamente o $24^{\circ}$ dia, o módulo GHB atua como um sumidouro de água, drenando o aqüífero. Portanto, quanto maior a condutância, mais eficiente é a drenagem, fazendo com que a carga hidráulica caia mais intensamente como resposta ao bombeamento realizado na Célula $(6,1)$. Na segunda etapa, o pacote GHB passa a atuar como uma fonte de água para o aqüífero, sendo esta alimentação mais eficiente quanto maior for a condutância, fazendo com que a carga hidráulica caia menos durante a simulação. 
Tabela 2. Resultados da análise de sensibilidade para o parâmetro Condutância

\begin{tabular}{cccc}
\hline $\begin{array}{c}\text { Condutância } \\
\left(\mathrm{m}^{2} / \mathrm{dia}\right)\end{array}$ & $\begin{array}{c}\text { Variação } \\
(\%)\end{array}$ & $\begin{array}{c}10 \text { dias } \\
\text { Carga }(\mathrm{m})\end{array}$ & $\begin{array}{c}80 \text { dias } \\
\text { Carga } \\
(\mathrm{m})\end{array}$ \\
\hline 1,6 & -80 & 846,28 & 832,08 \\
2,4 & -70 & 845,53 & 833,18 \\
3,2 & -60 & 844,91 & 834,08 \\
4 & -50 & 844,38 & 834,81 \\
4,8 & -40 & 843,93 & 835,41 \\
5,6 & -30 & 843,55 & 835,89 \\
6,4 & -20 & 843,22 & 836,29 \\
7,2 & -10 & 842,94 & 836,63 \\
8 & 0 & 842,69 & 836,91 \\
8,8 & 10 & 842,47 & 837,16 \\
9,6 & 20 & 842,28 & 837,37 \\
10,4 & 30 & 842,12 & 837,55 \\
11,2 & 40 & 841,97 & 837,71 \\
12 & 50 & 841,84 & 837,85 \\
12,8 & 60 & 841,72 & 837,98 \\
13,6 & 70 & 841,61 & 838,09 \\
14,4 & 80 & 841,52 & 838,19 \\
\hline
\end{tabular}

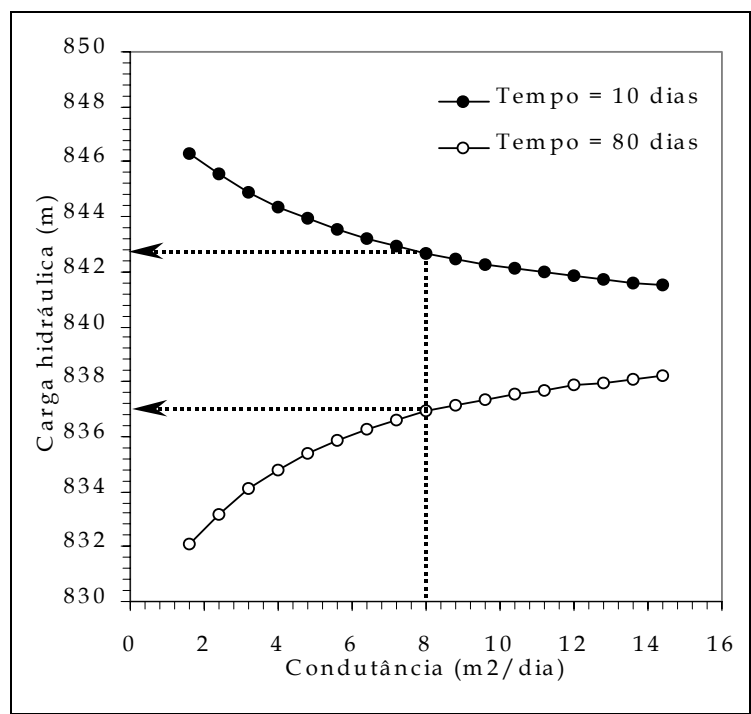

Figura 7. Cargas hidráulicas na Célula $(6,11)$, calculadas com o pacote $\mathrm{GHB}$, em função da condutância

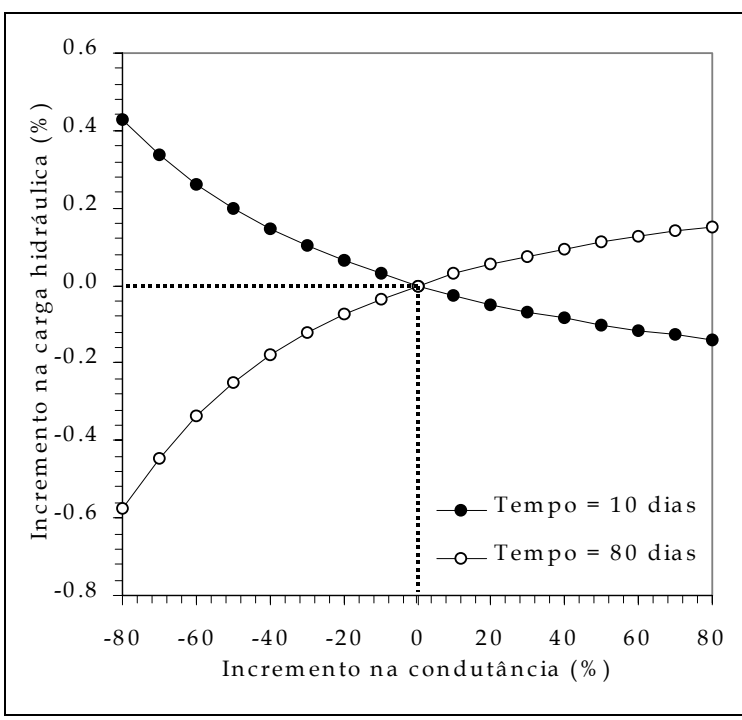

Figura 8. Variação da carga hidráulica na

Célula $(6,11)$, calculadas com o pacote GHB, em função da variação da condutância

Deve-se observar também que, quanto maior for a condutância, as cargas hidráulicas calculadas convergem ao valor da elevação $d, 840 \mathrm{~m}$, independentemente do tempo de simulação. Isso pode ser observado na Tabela 3 , que mostra os valores de carga calculados para três ordens de grandeza de valores de condutância, para os dois tempos de simulação considerados. Estes valores demonstram que, quando o parâmetro condutância atinge valores muito elevados, a condição de contorno de tipo 3 torna-se análoga à condição de tipo 1 , ou carga especificada, com carga igual à elevação $d$ da condição de tipo 3.

Tabela 3. Valores de carga hidráulica na Célula $(6,11)$ para três ordens de grandeza do parâmetro condutância.

\begin{tabular}{ccc}
\hline $\begin{array}{c}\text { Condutância } \\
\left(\mathrm{m}^{2} / \mathrm{dia}\right)\end{array}$ & $\begin{array}{c}10 \text { dias } \\
\text { Carga }(\mathrm{m})\end{array}$ & $\begin{array}{c}80 \text { dias } \\
\text { Carga }(\mathrm{m})\end{array}$ \\
\hline 100 & 840,16 & 839,73 \\
1000 & 840,01 & 839,97 \\
10000 & 840,00 & 840,00 \\
\hline
\end{tabular}

Outra observação interessante sobre as Figuras 7 e 8 é que há, claramente, uma tendência de queda na inclinação das curvas com o aumento do valor da condutância. Este fato pode ser explicado considerando que a descarga entre o contorno e o aqüífero é proporcional a dois termos: a condutância e a diferença entre a carga no aqüífero e o parâmetro $d$ (como mostra a Eq. 1). Como já discutido, quando a condutância torna-se muito elevada, a carga hidráulica 
no aqüífero tende a se igualar à elevação $d$ do contorno, fazendo com que o segundo termo da Eq. 1 se reduza. Com isso, a descarga é reduzida e, consequentemente, a variação da carga torna-se menos pronunciada.

\section{CONCLUSÃO}

Os módulos ou pacotes do modelo MODFLOW analisados neste trabalho, que são implementações da condição de contorno do tipo 3, embora matematicamente funcionem de forma similar, apresentam particularidades que os credenciam a ser usados não apenas para simular a relação entre sistemas aqüíferos e as condições hidrológicas sugeridas pelos seus nomes, mas também outras condições diferentes destas.

Por exemplo, o módulo Dreno pode ser usado para representar a relação entre um aqüífero e um rio temporário numa região semi-árida. De modo geral, aplica-se este pacote para simular drenos (abertos ou fechados), rios temporários, nascentes, trincheiras e qualquer outra condição que atue unicamente como sumidouro de água até um valor mínimo de carga hidráulica.

O Módulo Rio pode ser empregado para representar rios, lagos, represas e condições que assumam uma vazão constante de água para o aqüífero quando a carga hidráulica deste torna-se inferior a determinado valor. O módulo GHB também pode ser usado para modelar os sistemas hidrológicos simulados pelo Módulo Rio, entretanto, deve-se considerar que não haverá limite para o fluxo de água doado pelo contorno ao aqüífero. Esses dois módulos também podem ser usados como interface entre aqüíferos adjacentes simulados separadamente.

O pacote Evapotranspiração (EVT) é indicado para simular a relação de um aqüífero com terrenos alagados, mas também pode ser bem aplicado para representar drenos que possuam um valor limite para o fluxo máximo de drenagem, como é o caso de um dreno fechado, por exemplo.

A análise de sensibilidade realizada para o parâmetro condutância possibilitou verificar que quanto maior o valor desse parâmetro, mais as condições de contorno de tipo 3 se aproximam de uma condição de tipo 1 (carga especificada). Nessa situação, o aqüífero e a condição de contorno passam a se relacionar tal como vasos comunicantes, onde a carga hidráulica $h$ tende ao valor estipulado para o parâmetro $d$.

Este trabalho apresentou uma avaliação das condições de contorno de tipo 3 disponíveis no modelo MODFLOW sob uma ótica matemática. Entretanto, o processo de escolha do módulo mais adequado para descrever um determinado sistema físico deve ser baseado em uma avaliação criteriosa de dados de campo que caracterizem os mecanismos mais relevantes do sistema em estudo.

\section{AGRADECIMENTOS}

Os autores agradecem à FAPEMIG o financiamento do projeto através da concessão da bolsa de recém-doutor da co-autora Stela Cota (Projeto FAPEMIG TEC-00065/01).

\section{REFERÊNCIAS BIBLIOGRAFICAS}

[1] ANDERSON, M. P. e WOESSNER, G. M. (1992). Applied Groundwater Modelling. Academic Press, San Diego.

[2] FREEZE, R. A. e. CHERRY, J. A. (1979). Groundwater. Prentice-Hall, New Jersey.

[3] DOMENICO, P. A. e SCHWARTZ, F. W. (1997). Physical and Chemical Hydrogeology. $2^{\text {nd }}$ Edition, John Wiley \& Sons, New York.

[4] McDONALD, M. G. e HARBAUGH, W. (1988). A Modular Three-Dimensional Finite-Difference Ground-Water Flow Model. Washington D.C., EUA, p. 576. Techniques of Water-Resources Investigation, Book 6, Chapter A1, U.S. Geological Survey.

[5] ANDERSEN, P. F. (1993). A Manual of Instructional Problems for the U.S.G.S. MODFLOW Model. Ada, Oklahoma, EUA, p. 280. EPA/600/R-93/010, U.S. Environmental Protection Agency, Robert S. Kerr Environmental Research Laboratory.

[6] WATERLOO HYDROGEOLOGIC (2000). Visual MODFLOW, User's Manual, $v$. 2.8.2. Waterloo, Ontario, Canada, p. 311. Waterloo Hydrogeologic Inc. 